\title{
On a general theorem advanced by Prof. Clausius in reference to electrical influence
}

\section{G.J. Legebeke}

To cite this article: G.J. Legebeke (1880) On a general theorem advanced by Prof. Clausius in reference to electrical influence, Philosophical Magazine Series 5, 9:58, 458-460, DOI: $10.1080 / 14786448008626874$

To link to this article: http://dx.doi.org/10.1080/14786448008626874

曲 Published online: 28 Apr 2009.

Submit your article to this journal $\sqsubset \pi$

Џll Article views: 4

Q View related articles $\square$ 
high), falls into the capsule without wetting it, and instantly passes into the spheroidal state.

The experiment is recommenced in the open air when it rains or when hail is falling; and the results are the same as in the Panthéon experiment. Can it be said that in these experiments the water and the hail are sustained in the capsule by the vapour which envelops them? Certainly not; they are repelled instantaneously by the repellent force to which the heat in the capsule gives rise.

Let us now operate with non-volatile bodies, which cannot be distilled, but are decomposed by heat.

The capsule is heated as before, and small fragments of wax, tallow, stearic or margaric acid are then thrown into it, or else some drops of oleic acid or a fixed oil ; and this is what takes place :As the molecular motions are not transmitted with very great velocity, the body experimented on remains suspended over the capsule without vapour and without gas proceeding from its decomposition ; afterwards the gases resulting from its decomposition are liberated, not from its surface, but from its interior : they take fire, and the spheroid vanishes.

The body under experiment not being volatile, giving off no vapour, and the gases arising from its decomposition not being yet produced, evidently the body can only be sustained beyond the radius of the physico-chemical activity of the capsule by the repulsion of the latter.-Comptes Rendus de l'Académie des Sciences, May 3, 1880, t. xc. pp. 1074-1075.

ON A GENERAL THEOREM ADVANCED BY PROF. CLAUSIUS IN

REFERENCE TO ELECTRICAL INTLUENOE. BY G. J. LEGEBEKE.

In vol. i. of Wiedemann's Annalen* Prof. Clausius communicated a theorem on the connexion between the electrical charges of an arbitrary number of conductors which act by influence on one another. That author deems this theorem very general and new, and also assumes it in Part II. of his Mechanische Wärmetheorie, p. 33. I wish to point out that Clausius's is a special case of a more general principle, which, again, can itself be regarded as an extension of a well-known equation of Gauss's.

Over each of the closed surfaces $\mathrm{C}_{1}, \mathrm{C}_{2}$, \&c., named generally $\mathrm{C}$, a layer of a certain agent is spread, and acts by attraction or repulsion according to the usual laws. The density of the agent in points of

is represented by

$$
\mathrm{C}_{1}, \mathrm{C}_{2}, \text { \&c., } \mathrm{C} \text {, }
$$

$$
h_{1}, \quad h_{2}, \& c ., \quad h \text {, }
$$

and the potential of all these layers in the same points by

$$
\mathrm{V}_{1}, \mathrm{~V}_{2}, \text { \&c., } \mathrm{V} \text {. }
$$

Secondly, the layers upon $\mathrm{C}_{1}, \mathrm{C}_{2}$, \&e., $\mathrm{C}$, are replaced by layers

$$
\text { * See Phil. Mag. [5] iv. pp. } 454 \text { et seqq. }
$$


with the densities $\mathfrak{h}_{1}, \mathfrak{h}_{2}$, \&c., $\mathfrak{y}$, the potentials of which are

$$
\mathfrak{V}_{1}, \mathfrak{V}_{2} \text {, \&e., } \mathfrak{V} \text {. }
$$

Now, if $d w_{1}, d w_{2}, \& c ., d w$ represent the surface-elements of $\mathrm{C}_{1}, \mathrm{C}_{2}$, \&c., $\mathrm{C}$, or even

$$
\int V_{1} \mathfrak{h}_{1} d w_{1}+\int V_{2} \mathfrak{h}_{2} d w_{2}+\& c .=\int \mathfrak{B}_{1} h_{1} d w_{1}+\int \mathfrak{B}_{2} h_{2} d w_{2}+\& \mathbf{c} .,
$$

$$
\Sigma \int \nabla \mathfrak{b} d w=\Sigma \int \mathfrak{B} h d w \ldots \ldots \ldots \ldots \ldots
$$

holds good universally.

Before demonstrating this theorem, I remark that it can be applied directly to a number of conducting bodies $\mathrm{C}_{2}, \mathrm{C}_{2}$, \&c. charged with electricity in two different ways and acting by influence upon each other; for then the potentials $V$ and $\mathfrak{B}$ are constants expressing the potential-levels of the conductors, and equation (1) changes into the equation of Clausius.

In order to prove the above equality, we start, as Clausius did, from Green's well-known equation. This equation is employed for the space enclosed by the surface $\mathrm{C}$; and for the two functions occurring therein I take $V_{i}$ and $\mathfrak{V}_{i}$, of which the first represents the potential of all the layers with densities $h$, and the second the potential of the layers with densities $\mathfrak{b}$, both potentials taken in points within $\mathrm{C}$. We then have

$$
\int V_{i} \frac{d \mathfrak{B}_{i}}{d n} d w=\int \mathfrak{V}_{i} \frac{d V_{i}}{d n} d w
$$

The operation $\frac{d}{d n}$ is the differentiation with respect to the normal drawn within C. By successive applications of Green's theorem to the spaces enclosed by all the surfaces, we get, after summation,

$$
\Sigma \int V_{i} \frac{d \mathfrak{B}_{i}}{d n} d w=\Sigma \int \mathfrak{B}_{i} \frac{d \nabla_{i}}{d n} d w^{\prime} . \ldots \ldots
$$

Green's proposition is further applied to the space outside the surface $\mathrm{C}$, which space was first bounded by the surface of a sphere; the centre and radius were taken so that all the surfaces $C$ lay within the sphere. The potentials of the layers $h$ and $\mathfrak{b}$ in points outside the surfaces $\mathrm{C}$ are represented respectively by $\mathrm{V}_{a}$ and $\mathfrak{B}_{a}$, and these functions substituted in Green's equation. We then find, in the usual way, if the radius of the sphere be infinite,

$$
\Sigma \int V_{a} \frac{d \mathfrak{V}_{a}}{d \overline{\mathrm{N}}} d w=\Sigma \int \mathfrak{F}_{a} \frac{d \mathrm{~V}_{a}}{d \mathrm{~N}} d w \ldots \ldots
$$

The operation $\frac{d}{d \mathrm{~N}}$ is the differentiation with respect to the normal drawn outside of the surface $C$. The functions $V_{i}$ and $\nabla_{a}$ in equations (2) and (3) have of course the same value $V$ for the same point of one of the surfaces $C$; likewise the functions $\mathfrak{B}_{i}$ and $\mathfrak{B}_{a}$, which both change into $\mathfrak{B}$. It is not so with the differential quotients along the normal. 
The densities being $h$, let the potential of the layer on the surface $C$, in points within $\mathrm{C}$, be represented by $\mathrm{P}_{\boldsymbol{i}}$, and the potential of the other layers by $\mathrm{H}_{a}$; then is

and

$$
\frac{d \mathrm{~V}_{i}}{d n}=\frac{d \mathrm{P}_{i}}{d n}+\frac{d \mathrm{H}_{i}}{d n}
$$

Manifestly, for points of $\mathrm{C}$,

$$
\frac{d \mathrm{~V}_{a}}{d \mathrm{~N}}=\frac{d \mathrm{P}_{a}}{d \mathrm{~N}}+\frac{d \mathrm{H}_{a}}{d \mathrm{~N}}
$$

$$
\frac{d \mathrm{H}_{i}}{d n}=-\frac{d \mathrm{H}_{a}}{d \mathrm{~N}}
$$

and according to a known property $\frac{d \mathrm{P}_{i}}{d n}+\frac{d \mathrm{P}_{a}}{d \mathrm{~N}}=-4 \pi \epsilon h$, where $\epsilon$ represents a constant. Hence we find

$$
\frac{d V_{i}}{d n}+\frac{d V_{a}}{d \mathrm{~N}}=-4 \pi \epsilon h
$$

and in precisely the same way

$$
\frac{d \mathfrak{P}_{i}}{l n}+\frac{d \mathfrak{P}_{a}}{d \mathfrak{N}}=-4 \pi \epsilon \mathfrak{h}
$$

Therefore, by the summation of both members of equations (2) and (3), we get

$$
\Sigma \int \mathrm{Vh} d w=\Sigma \int \mathfrak{B} h d w .
$$

Lastly, I remark that this general equation is to be regarded as an extension of a property given by Gauss. Let $V$ represent the potential of a system of masses $m_{1}, m_{2}$, \&c. situated in the points $p_{1}, p_{2}, \& c$, and $\mathfrak{B}$ the potential of masses $\mathfrak{m}_{1}, \mathfrak{m}_{2}, \& c$. in the points $\mathfrak{p}_{1}, \mathfrak{p}_{2}$, \&c.; further, $V_{1}, V_{2}$, \&c. the values of $V$ in the latter points, and $\mathfrak{V}_{1}, \mathfrak{V}_{2}$, \&c. the values of $\mathfrak{B}$ in the points $p_{1}, p_{2}$, \&c.; then, according to Gauss,

$$
\begin{gathered}
\mathrm{V}_{\mathbf{l}} \mathrm{m}_{1}+\mathrm{V}_{2} \mathfrak{m}_{2} \quad \& c .=\mathfrak{V}_{1} m_{\mathfrak{l}} \mathfrak{B}_{2} m_{2}+\& c . \\
\Sigma \mathrm{V} \mathfrak{m}=\Sigma \mathfrak{B}_{m} .
\end{gathered}
$$

This equation is identical, since both members represent aggregates of the same combinations. That the theorem still remains valid when first the masses $m$ are spread out upon a surface $C$ and afterwards the masses $m$ upon the same surface, is not completely demonstrated by Gauss *, but "the way in which this extension of the theorem can be rigorously justified with respect to its principal moments only" pointed out.

In the foregoing this theorem is demonstrated for an arbitrary number of surfaces as a simple deduction from Green's equation.Wiedemann's Annalen, 1880, No. 5, x. pp. 154-158.

* Gauss, Allgemeine Lehrsätze in Beziehung auf die im verkehrten Verhältnisse des Quadrats der Entfernung wirTienden Kräfte, $\$ 19$. 